\title{
A Clinical Study of the Effectiveness of a Light Emitting Diode System on Tooth Bleaching
}

\author{
Roche Hayward, Yusuf Osman and Sias R. Grobler* \\ Oral and Dental Research Institute, Faculty of Dentistry, University of the Western Cape, Private Bag X1, Tygerberg \\ 7505, Cape Town, South Africa
}

\begin{abstract}
The purpose of this study was to evaluate the efficacy of a Light Emitting Diode (LED) System (BriteWhite) on tooth bleaching. Method: eeth 11 and 21 of twenty one subjects were treated in the chair with a LED light and 44\% carbamide peroxide gel, followed by an at-home treatment period of 14 days with $35 \%$ carbamide peroxide. The color of the teeth was measured with a spectrophotometer $\left(\mathrm{L}^{*} ; \mathrm{a}^{*} ; \mathrm{b}^{*}\right)$ before treatment (control) and after the above mentioned two stages. The subjects were also instructed to note tooth and gingival sensitivity. Results: For the $\mathrm{L}^{*}$ component a statistically significant difference $(\mathrm{p}<0.05)$ between base-line and directly after the LED treatment stage (whiter) was found and a complete relapse was found after the 14 day at-home treatment period. The $b^{*}$ component showed statistically significant differences $(\mathrm{p}<0.05)$ between base-line and the LED stage (less yellow more blue), with a further significant color improvement after the 14 day treatment period. For the $\mathrm{a}^{*}$ component (green to red) no statistically significant change was ( $>0.05$ ) found throughout the study (Wilcox on Signed Rank Sum Test). A major color change of 1.8 units ( $E_{a b}$ ) was found after the LED treatment stage with only a further small 0.2 unit improvement after the 14 day at-home treatment stage. Tooth and gingival sensitivity scores were low (below mild) throughout the treatment stages. Conclusion: A major tooth color increase was found after the in-office LED/gel treatment stage and only an insignificant further improvement was noted after the additional 14 day at-home treatment period. Only low tooth and gingival sensitivity scores were found. A slight increase in both the sensitivity and gingival scores after the LED/gel activated stage could be observed. Overall the total color increase was low.
\end{abstract}

Keywords: BriteWhite system, LED light, spectrophotometer, tooth whitener.

\section{INTRODUCTION}

Early in history humans started experimenting with the use of different chemicals to whiten their teeth for aesthetic purposes. However, the first commercial marketing of a $10 \%$ carbamide peroxide whitener occurred only in 1989 [1]. Nowadays various treatment modalities are available which include over-the-counter bleaching (self-administered), inoffice bleaching (professionally administered) and dentistsupervised take-home bleaching (professionally dispensed). Modern society desires to see the effect of bleaching immediately, resulting in higher concentrations of chemicals used in the composition of the whiteners [2] with different light sources believed to accelerate the bleaching process [3]. These high concentrations should only be applied by qualified people for control and prevention of possible damage to oral soft tissue. Today in-office bleaching mainly uses carbamide peroxide (CP) or hydrogen peroxide (HP) which might be activated by heat or light (with a chemical catalyst) to catalyze the tooth bleaching process [2,4]. It is believed that most light sources decompose peroxide faster (by increasing the temperature) to form free radicals which whiten teeth $[2,5,6]$. Various light sources are available, for example:

*Address correspondence to this author at the Oral and Dental Research Institute, Faculty of Dentistry, University of the Western Cape, Private Bag X1, Tygerberg 7505, Cape Town, South Africa; Tel: +27 937 3024;

Fax: +27937 3025; E-mail: srgrobler@uwc.ac.za light-emitting diodes (LED's), lasers, halogen lamps and plasma arc lamps (PAC). The most important point is that activation by heat, light or laser should not increase the intrapulpal temperature with more than $5.5^{\circ} \mathrm{C}$ [3] to avoid tooth damage.

However, strong controversy surrounds the success of light sources. Some researchers believe that it is effective in the bleaching process, while others believe only certain lights are effective and others reported no effect [4, 6-18]. Gurgan et al., 2010 [12] investigated the effect of 3 different light systems [diode laser, $810 \mathrm{~nm}$ on $37 \% \mathrm{HP}$; plasma arc lamp, 400-490 nm on 35\% HP; light emitting diode lamp on $38 \% \mathrm{HP}$ ] and found that the diode laser system gave the best tooth whitening $\left(\Delta \mathrm{E}^{*}{ }_{\mathrm{ab}} 5.69\right)$ and the least tooth sensitivity (on a 1-10 scale; 0.59 against approximately 3 ) as measured with a spectrophotometer. However, these differences were small and shade guide measurements gave no significant differences between the lights mentioned. Recently (2012) it was reported [16] that a halogen light is more effective than a laser light, while Hahn [17] (2012) could not find an improvement in tooth whitening as a result of LED or laser light treatments. He also reported no positive tooth color effect because of light treatment with an increase in tooth sensitivity. Hein (2003) [11] reported no difference in the whitening effect of bleaching gels [25\%-35\% (HP)] with or without 3 different lights. They concluded that the proprietary chemicals added to the bleaching gels acted as catalysts 
Table 1. The $25^{\text {th }}$ Percentile, Median (Med) and $75^{\text {th }}$ Percentile Values for $L^{*}$, $a^{*}$ and $b^{*}$ of 21 Subjects

\begin{tabular}{|c|c|c|c|}
\hline & L* & $\mathbf{a}^{*}$ & $\mathbf{b}^{*}$ \\
\cline { 2 - 4 } & $\mathbf{2 5 \%}$ Med 75\% & $\mathbf{2 5 \% ~ M e d ~ 7 5 \%}$ & $\mathbf{2 5 \%}$ Med 75\% \\
\hline \hline Baseline & 67.869 .870 .3 & -0.180 .040 .30 & 6.347 .548 .90 \\
\hline After LED & 69.370 .771 .4 & -0.150 .060 .31 & 5.366 .647 .93 \\
\hline After 14 days & 67.769 .169 .7 & $-0.35-0.160 .19$ & 5.446 .418 .08 \\
\hline
\end{tabular}

in the whitening process and were solely responsible for activation, where as the lights had no influence. From a laboratory study [6] where approximately $35 \%$ HP was used with different light sources (LED/diode laser, a halogen lamp, plasma arc lamp, argon laser) it can be summarized that nonactivated whitening did not differ from activated whitening. However, a combination of diode laser treatment with athome bleaching was reported to provide good results [18]. Another laboratory study reported that bleaching is more effective with a hybrid light-emitting diode (LED) and a low-intensity infrared diode laser than without it [13].

In a laboratory study [8] using six different photoactivation systems on three different 35\% hydrogen peroxide whiteners, it was found that only the diode laser, halogen lamp, and LED lamp showed significant color changes. Here it was concluded that the light source is more important than the bleaching agent in the whitening process. Kossatz (2011) [14] reported a larger difference in bleaching with a light-emitting diode [(LED)/laser] than without it (on $35 \%$ HP gel), with a shade guide value change of 4.8 vs. 3.8 units. However, tooth sensitivity was higher (53\% subjects) for the LED treated group but only $26 \%$ for the nonactivated group after 24 hours of treatment. Tooth sensitivity was also found to be persistent and higher when the LED activation was used.

In a recent (2011) critical appraisal [19] of power bleaching it was stated that light sources used in tooth whitening do not generate sufficient heat to damage teeth. They concluded that high concentrations of chemicals are responsible for faster whitening and that light sources are therefore superfluous in the whitening process.

The above literature clearly highlights the vast contradiction as to the effect of light activated whitening of teeth. Therefore, the purpose of this study was to determine the whitening effect of a relatively new Light Emitting Diode System (BriteWhite ${ }^{\circledR}$ Inc, Jasper, Alabama, USA).

\section{MATERIALS AND METHODOLOGY}

Twenty one subjects with two sound maxillary teeth (teeth 11 and 21), in good dental and medical health and not on any medical treatment, were selected. Smokers, subjects with fluorosis and tetracycline-stained or previously bleached teeth were excluded from the study. Before the start of the bleaching process teeth were polished with the Brite White polishing tool and paste [20] to remove any stains and plaque, rinsed and blot dried. The color of the teeth was then measured with a spectrophotometer (Model: CM-2600d, Konica Minolta Sensing, Inc., Japan) set on the CIE L*a*b* color space with a $6 \mathrm{~mm}$ diameter probe. Three measurements were taken $(6 \mathrm{~mm}$ diameter) at the center of the crown of the two different tooth types.
Thereafter the teeth were painted in-chair with the $44 \%$ carbamide peroxide gel (which included a photo initiator) using an application brush to achieve maximum tooth contact. A plastic cover was placed over the "U" shaped LED light mouthpiece to prevent contamination. The light was applied for a full cycle of 10 minutes, the gel wiped from the teeth, fresh peroxide gel applied and the light applied again. In this way three full cycles of 10 minutes each were applied.

The in-office session was then completed by having the patient rinse with the Brite White after-rinse solution for 30 seconds. The teeth were then blot dried and the color at the center of each tooth was measured again. Patients were instructed to refrain from eating or drinking foodstuffs rich in color for the first 48 hours after the LED bleaching stage. The patients were requested to note any tooth sensitivity or gingival irritation before treatment, after the LED treatment and after the 14 day at-home treatment period and to rank it in terms of none (1), mild (2), moderate (3) or severe (4).

Customized bleaching trays were provided for each patient and subjects were instructed to apply the $35 \%$ carbamide peroxide bleach system daily for 30 minutes for a 14 day period. Patients were instructed to brush gently and not to floss before the bleaching process, according to Brite White instructions. After each at-home application patients were instructed to rinse with water but not to eat or drink anything high in color for at least an hour.

The Wilcox on Signed Rank Sum Test was used to determine the significance of the results.

Full written ethical approval for the project was obtained from the Ethical and Research Committee of the University of the Western Cape.

\section{RESULTS}

For the statistical tests we computed $\mathrm{L}^{*}, \mathrm{a}^{*}, \mathrm{~b}^{*}$ and $\Delta \mathrm{E}^{*}{ }_{\mathrm{ab}}$ over time by subtracting the follow-up measurements from baseline measurements [21] and determined the color change by comparing each after bleaching to baseline.

No statistically significant difference in all three components ( $\mathrm{L}^{*}, \mathrm{a}^{*}$ and $\mathrm{b}^{*}$ ) between teeth 11 and 21 were found. Therefore, the values of teeth 11 and 21 were pooled in the statistical analysis.

Table 1 gives the $25^{\text {th }}$ percentile, median and $75^{\text {th }}$ percentile of the $\mathrm{L}^{*}$ values at base-line (before treatment), after the LED treatment, as well as after the 14 day at-home treatment period. It also shows the same for the $a^{*}$ values, and for the $b^{*}$ values over time. Fig. (1) gives the total color change differences $\left(\Delta \mathrm{E}^{*}{ }_{\mathrm{ab}}\right)$ after the LED treatment as well as after the 14 day at-home treatment. 


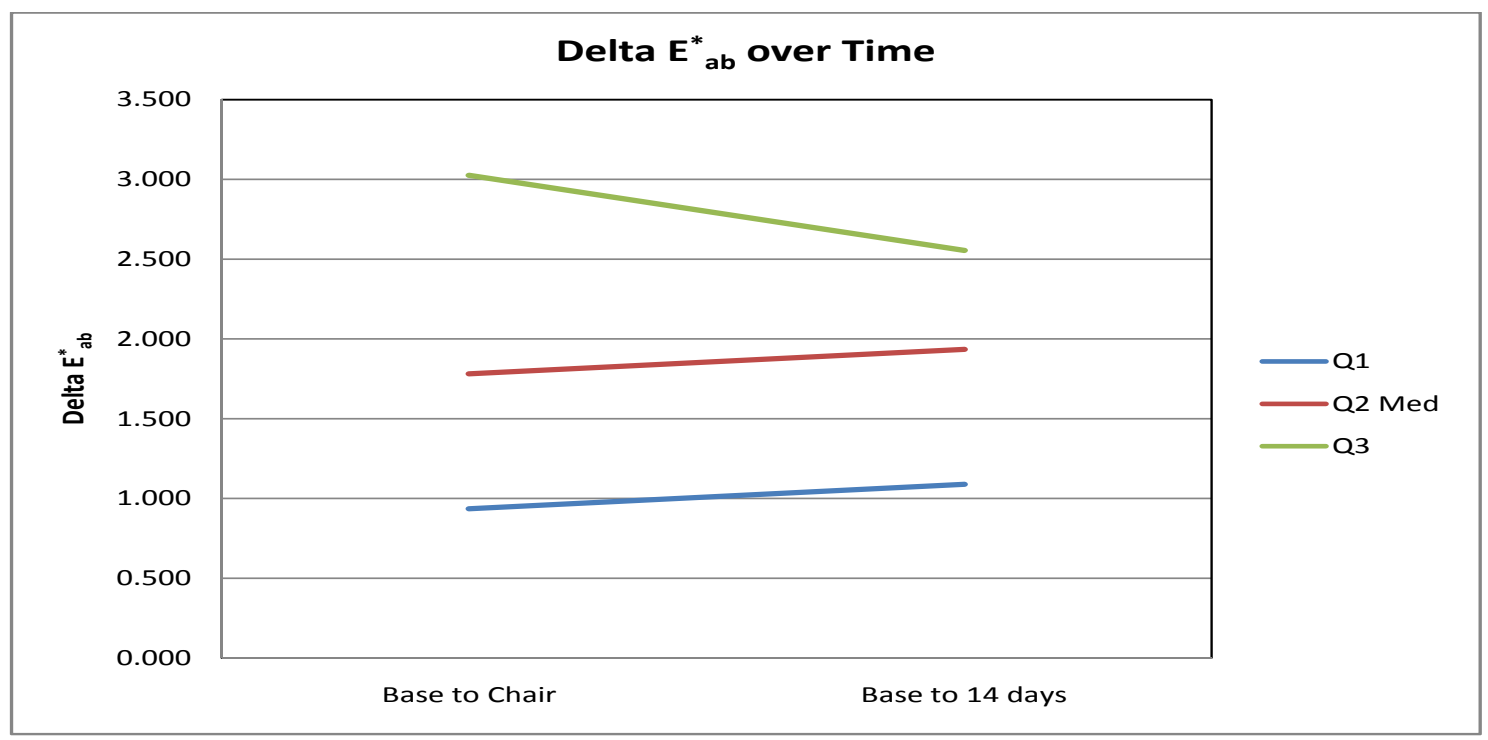

Fig. (1). A graph of the $25^{\text {th }}$ percentile $(\mathrm{Q} 1)$, median $(\mathrm{Q} 2)$ and $75^{\text {th }}$ percentile $(\mathrm{Q} 3)$ for the median $\Delta \mathrm{E}^{*}{ }_{\mathrm{ab}}$ values between base-line (before treatment) and after the LED treatment, as well as between baseline and after the 14 day full treatment period $(n=21)$.

Table 2. Tooth and Gingival Sensitivity Scores of Means with Standard Deviation in Brackets after LED Treatment and after 14 Daystreatment $(n=21)$

\begin{tabular}{|c|c|c|c|}
\hline & Base-line & After LED & After 14 days \\
\hline \hline Teeth S & $0.33(0.48)$ & $0.43(0.60)$ & $0.37(0.50)$ \\
\hline Gingival S & $0.00(0.00)$ & $0.57(0.60)$ & $0.32(0.95)$ \\
\hline
\end{tabular}

For the $\mathrm{L}^{*}$ component (Table $\left.\mathbf{1}\right)$ a statistically significant difference $(\mathrm{p}<0.05)$ in the median values between base-line and just after the LED treatment stage (whiter) was found, but a significant relapse to the original value was also found after the 14 day treatment period (Wilcox on Signed Rank Sum Test). The $b^{*}$ component showed statistically significant differences $(p<0.05)$ between base-line and the LED stage (reduced yellow), between base-line and the 14 day stage (further reduced yellow) as well as between the LED treatment stage and after the 14 day treatment period (least yellow) (Wilcox on Signed Rank Sum Test). For the a* component no statistically significant change was $(p>0.05)$ found throughout (Table 1).

The total color increase $\left(\Delta \mathrm{E}^{*} \mathrm{ab}\right)$ was 1.8 units after the LED treatment stage with no significant change after the 14 day at-home treatment period (Fig. 1).

Table 2 gives the mean and standard deviation of the tooth sensitivity and gingival sensitivity scores ranked in terms of none (1), mild (2), moderate (3) and severe (4).

Both the tooth and gingival sensitivities were found to be very low (below one) as the median values (Table 2 ) did not even reach a score of one unit (mild). There was a slight insignificant increase in both the sensitivity and gingival scores after the LED activated stage.

\section{DISCUSSION}

Today LED lights are available across the visible, ultraviolet and infrared spectrum of wavelengths. The LED light system investigated in this study [20] is marked as a blue LED light which means the wavelength should be between 450 and $500 \mathrm{~nm}$ [22]. It is also reported that LEDs can emit light of an intended color without using any color filters as in traditional lighting methods. This BriteWhite tooth whitening system [20] is claimed to have an activating gel which prevents heat formation, has no sensitivity to teeth, prevents pulp damage, has a blue LED light with a tailored wavelength to activate their custom made gel and can whiten teeth with up to 11 shade tabs within 20 minutes. Furthermore it is FDA cleared while the LED light is also believed to boost the healing of mouth ulcers, cold sores and periodontal diseases.

In this study the color change was measured with a sophisticated spectrophotometer (Model: CM-2600d, Konica Minolta Sensing, Inc., Japan) and not with a shade guide. Using a spectrophotometer has many advantages over shade guides [5, 6, 23-29]. The most important are improved accuracy and quantification of colors by measurement in a three dimensional color space $\left(\mathrm{L}^{*} \mathrm{a}^{*} \mathrm{~b}^{*}\right)$ [30] [Minolta]. In this space $\mathrm{L}^{*}$ indicates lightness/darkness (white/black), $\mathrm{a}^{*}$ varies from green (negative side) to red (positive side), while the $b^{*}$ value varies from blue (negative side) to yellow (positive side). On the other hand a shade guide can only provide a total color value, resulting in the loss of important information on the type of color change mentioned above. Furthermore, differences in results can be expected when color evaluation is done with shade guides versus a spectrophotometer as was previously reported [12, 29, 31-36].

The differing results reported with different tooth bleaching systems can be attributed to various factors such as: base-line color of the teeth of the chosen subjects, the type and concentration of the bleaching product, the time period for the in-chair treatment as well as the treatment period and concentration of the products. ThisBriteWhite/LED system can be seen as a mild treatment system for the following reasons: Firstly, the in-chair LED stage treatment uses a relatively low peroxide concentration (44\% carbamide peroxide equivalent to $\sim 15 \% \mathrm{HP}$ ) whereas hydrogen peroxide concen- 
trations of approximately $35 \%$ are normally used [12, 13 , 18]. Secondly, the LED treatment period comprised only 3 ten minute sessions vs. reported [18] 2 twenty minute sessions. Thirdly, the at-home bleaching stage was 14 days, for 30 minutes per day with a low $35 \%$ carbamide peroxide (equivalent to $\sim 12 \% \mathrm{HP}$ ) whitener where most at-home bleaching was done for hours over-night [26,27]. The main advantage of such a mild BriteWhite system is that the gingival and sensitivity scores were found to be very low (below mild, Table 1). The large spread of results (Fig. (1) and Table 1) can be attributed to the fact that the base-line color of the teeth was not a selection criteria and the whitening of enamel varies between subjects. Such a large spread of results during whitening has been reported previously [26-28].

Gurgan, et al., 2010 [12] reported a considerably higher total color change than found in this study $\left(\Delta \mathrm{E}^{*}{ }_{\mathrm{ab}}=5.43 \mathrm{vs}\right.$. our 1.8) also using an LED lamp but with a much higher hydrogen peroxide $(38 \%)$ concentration and on A3 or darker teeth. This should at least partly explain the higher total color change relative to our study. In agreement with our study their LED lamp also showed a low gingival score (mean 2.9 on a 10 point scale) and low tooth sensitivity (mean 1.1 on a 10 point scale). We only found (Table 2) a small insignificant increase in the tooth sensitivity after the LED treatment, which returned to the base-line value after the 14 day at-home treatment period. However, the gingival score increased from 0 to 0.57 (Table 2) as a result of the LED stage treatment but improved slightly after the 14 day at-home treatment (0.32).

The 14 day at-home bleaching (Fig. 1) could only contribute a further increase of 0.2 units but according to AlQuar an [18] an improved and more persistent effect could be seen when the bleaching process was longer (3 months).

In a clinical study [12] differences in all 3 the components ( $L^{*}, a^{*}$ and $\left.b^{*}\right)$ were found for their LED system on $38 \%$ HP. The teeth were found to be whiter ( $\mathrm{L}^{*}$ ) with 5.2 units, less red ( $\left.a^{*}\right)$ with 0.9 units and less yellow ( $\left.b^{*}\right)$ with 1.7 units. These improvements were much higher than found in our study ( $\left.L^{*}=1.0 ; \quad a^{*}=0.02 ; \quad b *=0.9\right)$ just after the LED treatment. As found throughout in this study, teeth whitening systems only provided small unit changes in the $a^{*}$ values relative to the $L^{*}$ and $b^{*}$ values $[13,23$ $25,30,34-39]$. In research on stained teeth with $35 \% \mathrm{HP}$ and LED treatment, where only a $\mathrm{L}^{*}$ change was measured, a much higher improvement than in this study (4 units) was reported [7]. In a laboratory study [4] very similar results for

$\mathrm{L}^{*}$ (4.7) and for a LED light on $35 \%$ hydrogen peroxide were reported $\left(\mathrm{L} *=4.7 ; \quad \mathrm{a}^{*}=1.7 ; \quad \mathrm{b} *=-3.6\right.$ and $\Delta \mathrm{E}^{*}{ }_{\mathrm{ab}}$ $=6.4$ ). In another laboratory study [8] also using a LED light and $35 \% \mathrm{HP}$, a Vita Shade guide value improvement of about 5.3 units was reported which can be considered relatively high. In this study (Table 1) it can be seen that the $b^{*}$ component was the only component which improved (less yellow) throughout the two application stages, while the $\mathrm{L}^{*}$ component initially improved (whiter) and then showed a total relapse to the original value.

\section{CONCLUSION}

This is a low peroxide concentration/LED system. The major tooth color increase was found after the in-office
LED/gel treatment stage and only an insignificant further improvement was noted after the additional 14 day at-home treatment period. Only low tooth and gingival sensitivity scores were recorded. A slight increase in both the sensitivity and gingival scores after the LED/gel activated stage could be observed. Overall the total color increase was relatively low.

\section{ACKNOWLEDGMENT}

This study was financially supported by the DDF fund of the South African Dental Association. Disclaimer: The South African Dental Association does not necessarily support the findings or conclusions made in this article.

\section{CONFLICT OF INTEREST}

The authors confirm that this article content has no conflicts of interest.

\section{CLINICAL RELEVANCE}

The BriteWhite ${ }^{\circledR}$ system can be used as an average tooth whitener with low tooth and gingival sensitivity.

\section{REFERENCES}

[1] Khin PW, Barnes DM, Romberg E, Peterson K. A clinical evaluation of $10 \%$ vs. $15 \%$ carbamide peroxide tooth-whitening agents. J Am Dent Assoc 2000; 131:1478-84.

[2] Sulieman M, Addy M, MacDonald E, Rees JS. The effect of hydrogen peroxide concentration on the outcome of tooth whitening: an in vitro study. J Dent 2004; 32: 295-9.

[3] Buchalla W, Attin T. External bleaching therapy with activation by heat, light or laser: a systematic review. Dent Mat 2007; 23: 58696.

[4] Zhang C, Wang X, Kinoshita, et al. Effects of KTP laser irradiation, diode laser and LED on tooth bleaching: a comparative study. Photomed Laser Surg 2007; 25: 91-5.

[5] Joiner A. Tooth colour: a review of the literature. J Dent 2004; 32: 3-12.

[6] Lima DA, Aguiar FH, Liporoni PC, Munin E, Ambrosano GM, Lovadino JR. In vitro evaluation of the effectiveness of bleaching agents activated by different light sources. J Prosthodont 2009; 18: 249-54.

[7] Wetter NU, Barroso MCS, Pelino JEP. Dental bleaching efficacy with diode laser and LED irradiation: an in vitro study. Lasers Surg Med 2004; 35: 254-8.

[8] Domínguez A, García JA, Costela A, Gómez C. Influence of the light source and bleaching gel on the efficacy of the tooth whitening process. Photomed Laser Surg 2011; 29: 53-9. [Epub 2010; Oct 22].

[9] Luk K, Tam L, Hubert M. Effect of light energy on peroxide tooth bleaching. J Am Dent Assoc 2004; 135: 194-201.

[10] Tavares M, Stultz J, Newman M, et al. Light augments tooth whitening with peroxide. J Am Dent Assoc 2003; 134:167-75.

[11] Hein DK, Ploeger BJ, Hartup JK, Wagstaff RS, Palmer TM, Hansen LD. In-office vital tooth bleaching: what do they add? Compend Contin Educ Dent 2003; 24: 340-52.

[12] Gurgan S, Filiz YC, Esra Y. Different light-activated in-office bleaching systems: a clinical evaluation. Lasers Med Sci 2010; 25: 817-22.

[13] Torres CR, Barcellos DC, Batista GR, Borges AB, Cassiano KV, Pucci CR. Assessment of the effectiveness of light-emitting diode and diode laser hybrid light sources to intensify dental bleaching treatment. Acta Odontol Scand 2011; 69:176-81.

[14] Kossatz S, Dalanhol AP, Cunha T, Loguercio A, Reis A. Effect of light activation on tooth sensitivity after in-office bleaching. Oper Dent 2011; 36: 251-7.

[15] D'Arce MB, Lima DA, Aguiar FH, Ambrosano GM, Munin E, Lovadino JR. Evaluation of ultrasound and light sources as bleaching catalysts: an in vitro study. Eur J Esthet Dent 2012; 7: 176-84. 
[16] Polydorou O, Wirsching M, Wokewitz M, Hahn P. Three-month evaluation of vital tooth bleaching using light units: a randomized clinical study. Open Dent 2012 Jul 7. [Epub ahead of print]. Retrieved 18 July 2012 from: http://www.ncbi.nlm.nih.gov/pubmed?term=Polydorou $\% 202012$

[17] Hahn P, Schondelmaier N, Wolkewitz M, Altenburger MJ, Polydorou O. Efficacy of tooth bleaching with and without light activation and its effect on the pulp temperature: an in vitro study. Odontology 2012 Mar 1. [Epub ahead of print]. Available from: http://www.ncbi.nlm.nih.gov/pubmed?term=Hahn\%20P\%2C\%20S chondelmaier $\% 20 \mathrm{~N} \% 2 \mathrm{C} \% 20 \mathrm{Wolkewitz} \% 20 \mathrm{M} \% 2 \mathrm{C} \% 20$ Altenburger\%20MJ\%2C\%20Polydorou\%20O\%202012

[18] Al Quran FA, Mansour Y, Al-Hyari S, Al Wahadni A, Mair L. Efficacy and persistence of tooth bleaching using a diode laser with three different treatment regimens. Eur J Esthet Dent 2011; 6: 43645.

[19] Browning WD, Swift EJ Jr. Power bleaching. J Esthet Restor Dent 2011; 23: 61-7.

[20] BEKS. 2011. Brite Whiteteeth whitening system. BEKS Inc. Retrieved 18 July 2012 from: http://www.britewhitemini.com/

[21] Commission Internationale de I'Eclairage. Recommendations on uniform color space, color difference equations, psychometric color terms. Suppl 2 to CIE publication 1978; 15 Paris: Bureau Central de la CIE.

[22] Light-emitting diode. Colors and materials. Retrieved online January 2012. Available from: http://en.wikipedia.org/wiki/Lightemitting diode

[23] Derdilopoulou FV, Zantner C, Neumann K, Kielbassa AM. Evaluation of visual and spectrophotometric shade analyses: a clinical comparison of 3758 teeth. Int J Prosthodont 2007; 20: 414-6.

[24] Kielbassa AM, Beheim-Schwarzbach NJ, Neumann K, Nat R, Zantner C. In vitro comparison of visual and computer-aided preand post-tooth shade determination using various home bleaching procedures. J Prosthet Dent 2009; 101: 92-100.

[25] Paul S, Peter A, Pietrobon N, Hämmerle CH. Visual and spectrophotometric shade analysis of human teeth. J Dent Res 2002; 81: 578-82.

[26] Grobler SR, Hayward R, Wiese S, Moola MH. Spectrophotometric assessment of the effectiveness of Opalescence PF 10\%: a 14month clinical study. J Dent 2010; 38(2):113-7. [Epub 2009 Sep 23].
[27] Grobler SR, Majeed A, Moola MH, Rossouw RJ, Kotze TJ van W. In vivo spectrophotometric assessment of the tooth whitening effectiveness of Nite White $10 \%$ with amorphous calcium phosphate, potassium nitrate and fluoride, over a 6-month period. Open Dent J 2011; 5:180-4.

[28] Grobler SR, Majeed A, Hayward R, Rossouw RJ, Moola MH, Kotze TJ van W. Clinical study of the effectiveness of two different 10\% Carbamide peroxide bleaching products: a 6- month followup. Int J Dent 2011; 2011: 167525. [Epub 2011 May 5].

[29] Horn D, Bulan-Brady J, Hicks M. Sphere spectrophotometer versus human evaluation of tooth shade. J Endod 1998; 24: 786-90.

[30] Minolta, Precise color communication, Minolta, Co., Ltd., Osaka Japan 1994; 9242-4830-92 IHCAJ.

[31] Marson FC, Sensi LG, Vieira LCC, Araujo E. Clinical evaluation of in-office dental bleaching treatments with and without the use of light-activation sources. Oper Dent 2008; 33:15-22.

[32] Lin CH, Chou TM, Chen JH, et al. Evaluation of the effect of laser tooth whitening. Int J Prosthodont 2008; 21: 415-8.

[33] Meireles SS, Heckmann SS, Santos IS, Della Bona A, Demarco FF.A double blind randomized clinical trial of at-home tooth bleaching using two carbamide peroxide concentrations: 6-month follow-up. J Dent 2008; 36: 878-84.

[34] dos Santos Medeiros MC, de Lima KC. Effectiveness of nightguard vital bleaching with $10 \%$ carbamide peroxide: a clinical study. J Can Dent Assoc 2008; 74(2): 163-3e.

[35] Ritter AV, Leonard RH Jr, St Georges AJ, Caplan DJ, Haywood VB. Safety and stability of nightguard vital bleaching: 9 to 12 years post-treatment. J Esthetic Restor Dent 2002; 14: 275-85.

[36] Goo DH, Kwon TY, Nam SH, Kim HJ, Kim KH, Kim YJ. The efficiency of $10 \%$ carbamide peroxide gel on dental enamel. Dent Mater J 2004; 23: 522-7.

[37] Luo W, Westland S, Brunton P, Ellwood R, Pretty IA, Mohan N. Comparison of the ability of different color indices to assess changes in tooth whiteness. J Dent 2007; 35:109-16.

[38] Ishikawa-Nagai S, Terui T, Ishibasi K, Weber HP, Ferguson M. Comparison of effectiveness of two $10 \%$ carbamide peroxide toothbleaching systems using spectrophotometric measurements. J Esthet Restor Dent 2004; 16: 368-75.

[39] American Dental Association. ADA Acceptance Program Guidelines Dentist dispensed home-use tooth bleaching products ADA council on scientific affairs 2006. Retrieved online May 2009 from: http://www.ada.org/ada/seal/standards/guide_home_bleach.pdf

Received: June 17, 2012

Revised: June 20, 2012

Accepted: August 20, 2012

(C) Hayward et al.; Licensee Bentham Open.

This is an open access article licensed under the terms of the Creative Commons Attribution Non-Commercial License (http://creativecommons.org/licenses/by-nc/3.0/) which permits unrestricted, non-commercial use, distribution and reproduction in any medium, provided the work is properly cited. 